\title{
Quantification of different microplastic fibres discharged from textiles in machine wash and tumble drying
}

\author{
Niina Kärkkäinen ${ }^{1} \cdot$ Markus Sillanpää ${ }^{1}$ (10 \\ Received: 18 April 2020 / Accepted: 6 December 2020 / Published online: 18 December 2020 \\ (C) The Author(s) 2020
}

\begin{abstract}
Microplastic fibres released in synthetic cloth washing have been shown to be a source of microplastics into the environment. The annual emission of polyester fibres from household washing machines has earlier been estimated to be $150,000 \mathrm{~kg}$ in a country with a population of $5.5 \times 10^{6}$ (Finland). The objectives of this study were (1) to quantify the emissions of synthetic textile fibres discharged from five sequential machine washes (fibre number and length) and tumble dryings (fibre mass) and (2) to determine the collection efficiency of two commercial fibre traps. The synthetic fabrics were five types of polyester textiles, one polyamide and one polyacryl. The number of fibres released from the test fabrics in the first wash varied in the range from $1.0 \times 10^{5}$ to $6.3 \times$ $10^{6} \mathrm{~kg}^{-1}$. The fibre lengths showed that the fleece fabrics released, on average, longer fibres than the technical sports t-shirts. The mass of fibres ranged from 10 to $1700 \mathrm{mg} / \mathrm{kg} \mathrm{w} / \mathrm{w}$ in the first drying. Fibre emissions showed a decreasing trend both in sequential washes and dryings. The ratio of the fibre emissions in machine wash to tumble drying varied between the fabrics: the ratio was larger than one to polyester and polyamide technical t-shirts whereas it was much lower to the other tested textiles. GuppyFriend washing bag and Cora Ball trapped 39\% and 10\% of the polyester fibres discharged in washings, respectively.
\end{abstract}

Keywords Microplastic $\cdot$ Polyester $\cdot$ Polyamide $\cdot$ Polyacryl $\cdot$ Washing machine $\cdot$ Tumble drier $\cdot$ Household $\cdot$ Emission

\section{Introduction}

Plastics are synthetic materials made from mixtures of organic polymers and additives. They are used in a wide range of applications due to their low cost, ease of manufacture and many advantageous properties. In the year 2018, the world plastic production reached 359 million tonnes (Plastics 2019), a number which is expected to still rise in the future. During the last decade, microplastics have been observed in different kinds of environments all over the world which has raised concern in both the scientific community and the public. Microplastics are often defined as small solid synthetic polymer particles with the largest dimension less than $5 \mathrm{~mm}$ and the smallest dimension equal to $1 \mu \mathrm{m}$. They may contain functional additives and possible residual impurities such as bisphenol A, phthalates, flame retardants and UV absorbers.

Responsible Editor: Philippe Garrigues

Markus Sillanpää

markus.sillanpaa@syke.fi

1 Laboratory Centre, Finnish Environment Institute, Mustialankatu 3, FIN-00790 Helsinki, Finland
Microplastics have a large surface-area-to-volume ratio that contributes to their ability to act as vectors for different kinds of hydrophobic substances in the environment (Lee et al. 2014). The small size of the microplastics also makes them available for ingestion by small organisms ( $\mathrm{Su}$ et al. 2018; Alomar and Deudero 2017; Hurley et al. 2017; Setälä et al. 2014).

Microplastics have been observed in numerous environments like the marine (Cincinelli et al. 2017; van der Hal et al. 2017; Lusher et al. 2015), freshwater (Rodrigues et al. 2018; Fischer et al. 2016; Mani et al. 2015) and terrestrial (Scheurer and Bigalke 2018; Zhang et al. 2018; Sruthy and Ramasamy 2017) environments. Although the numerous sources of microplastics have been identified, the quantitative contributions, pathways to the different environment compartments, environmental fate and ecological effects of microplastics are still largely unknown (Wang et al. 2020). Some of the previously identified microplastic sources include car tyres, personal care products, and synthetic textiles (Galafassi et al. 2019). The latter one has been determined to be a major source of microplastic fibres originating from textile laundering (Henry et al. 2019). The shed fibres travel from a washing machine into domestic wastewater which then 
enters a wastewater treatment plant. In Finland alone, the emissions of the most common synthetic fibres, i.e. polyester, from household machine washing, has been estimated to be $150,000 \mathrm{~kg}$ per year (Sillanpää and Sainio 2017).

The earlier studies have shown that the majority ( $\geq 98 \%$ ) of the microplastics are removed from the wastewater when secondary and/or tertiary treatment processes are being used (e.g. Lares et al. 2018; Carr et al. 2016; Michielssen et al. 2016; Murphy et al. 2016; Talvitie et al. 2017; Magnusson and Norén 2014). The removed microplastics end up into sewage sludge during wastewater cleaning processes. The sewage sludge can then be applied onto a soil where microplastics may adversely affect soil animals (Selonen et al. 2020).

While domestic washing of synthetic textiles has been determined to be a significant source of microplastics entering the environment, fibre release from textiles is not yet well understood. Among these studies, polyester has been the most researched textile material due to its prevalence in the clothing industry (Carmichael 2015). In addition, some studies have included other textile materials, such as polyamide (Cesa et al. 2020; Yang et al. 2019; Carney Almroth et al. 2018; Hartline et al. 2016), polyacryl (Cesa et al. 2020; Carney Almroth et al. 2018; Napper and Thompson 2016) and blends of these materials (Corami et al. 2020; Belzagui et al. 2019). Previous studies have investigated the effects of washing conditions on fibre release, such as the use of detergent (Cesa et al. 2020; Corami et al. 2020; Kelly et al. 2019; Yang et al. 2019; Zambrano et al. 2019; Carney Almroth et al. 2018; De Falco et al. 2018; Hernandez et al. 2017) and the effects of sequential washing (Cesa et al. 2020; Belzagui et al. 2019; De Falco et al. 2019; Kelly et al. 2019; Zambrano et al. 2019; Carney Almroth et al. 2018; Hernandez et al. 2017; Sillanpää and Sainio 2017; Pirc et al. 2016; Napper and Thompson 2016). Fibre emission mitigating technologies have been in the focus of research only in three previous scientific papers: McIlwraith et al. (2019) investigated the collection efficiencies of two commercially available fibre traps, Cora Ball laundry ball and Lint LUV-R filter, whereas Yang et al. (2019) and Cesa et al. (2020) studied collection efficiencies of built-in filters of different washing machines.

This study focuses on the emissions of different synthetic fibres and their reduction during laundering. Microscopic and gravimetric analyses were done the determination of the synthetic fibres released in machine washes and tumble dryings, respectively. The objectives of the study are (1) to quantify the fibre release from five sequential cycles of machine wash and tumble drying and (2) to determine the collection efficiency of two commercial fibre traps. This is the first study that has investigated the fibre release from different synthetic textile materials in sequential tumble dryings and the collection efficiency of Guppyfriend washing bag.

\section{Materials and methods}

\section{Textiles}

Five different types of polyester textiles, one type of polyamide t-shirt and one type of polyacryl jumper were selected for the study (Table 1): polyester anti-pill fleece fabric (PES-fap), polyester fleece blankets (PES-fnap), polyester softshell fabric (PES-ss), polyester technical sports t-shirts (PES-ts1 and PESts2), polyamide technical sport t-shirts (PA-ts) and acryl jumpers (PAN-je). All the textiles studied were new and unused, with bright colours to differentiate them from each other. The textiles were also analysed with a scanning electron microscopy (ZEISS EVO 15) to the determination of fabric and yarn characteristics (Fig. 1). The sample textiles were sputtercoated with gold and analysed with a $20-\mathrm{kV}$ electron beam. Finally, two different types of new and unused $100 \%$ polyester technical sports t-shirts (six dark grey and six green ones) were selected for the fibre trap experiments.

\section{Machine washes and tumble drying}

The synthetic textiles were washed with a front-load washing machine (Bosch WAE28477SN) using $50 \mathrm{ml}$ of liquid detergent ( $\mathrm{pH}=8.0$; Bio Luvil Color, Unilever). All the textiles were separately washed with the wash program "Mix" with the settings as follows: water temperature $40^{\circ} \mathrm{C}$, spin-dry rate 1200 and total duration $75 \mathrm{~min}$. Prior to each wash, the unloaded machine was cleaned with the liquid detergent by three times running the wash program "Super fast." The settings of the wash programs have been detailed in Sillanpää and Sainio (2017). After each wash, the textiles were consequently dried in a front-load tumble drier (Bosch Serie 4). The program used for the tumble drying was "Timed Program Warm," with the drying time of $50 \mathrm{~min}$ and with the "low heat" function turned on for a reduced temperature of $45^{\circ} \mathrm{C}$. Each textile went through five sequential washing-drying cycles.

The whole washing effluent was sampled into a large polyethylene barrel. Sub-sampling was done by taking three aliquots from the continuously stirred effluent water, with the volume varying from 50 to $1000 \mathrm{ml}$ depending on the fibre concentration. The aliquots were then filtered through a gridded mixed-cellulose ester filter (diameter $47 \mathrm{~mm}$, pore size $0.7 \mu \mathrm{m}$, type HC, Millipore, Bedford, MA, USA). The sub-sampling and filtration were done directly after each wash. The potential remaining fibres in the sub-sample containers were rinsed out with deionised water and then filtered. The wet filters were dried inside petri dishes with caps ajar in a laminar flow hood overnight. The sampling was described in detail by Sillanpää and Sainio (2017). In the tumble-drying experiments, the fibres were collected and rinsed off from the 
Table 1 Descriptions of the seven synthetic textiles used for washing and tumble drying

\begin{tabular}{lllllll}
\hline Sample & Description & Textile label & Area $\left(\mathrm{m}^{2}\right)$ & Mass $(\mathrm{g})$ & Thickness (mm) & Colour \\
\hline PES-fap & One fabric, fleece, anti-pill & $100 \%$ polyester & 3.44 & 742.9 & 2.5 & Red \\
PES-fnap & Two blankets, fleece, not anti-pill & $100 \%$ polyester & 5.00 & 679.4 & 0.15 & Light blue \\
PES-ss & One softshell fabric & $96 \%$ polyester, $4 \%$ elastane & 3.37 & 1051.6 & 0.90 & Orange and violet sides \\
PES-ts & Four technical sport t-shirts & $100 \%$ polyester & 1.31 & 183.7 & 0.03 & Two pink \\
PES-ts1 & & & 1.63 & 253.5 & 0.05 & Two green \\
PES-ts2 & Four technical sport t-shirts & $92 \%$ polyamide, $8 \%$ elastane & 2.34 & 654.3 & 0.06 & Two blue, two black \\
PA-ts & $\quad$ (same shirts, different colours) & $100 \%$ acryl & 1.64 & 575.1 & & olive green \\
PAN-je & Two jumpers & & &
\end{tabular}

lint filter (mesh size $60 \mu \mathrm{m}$ ), then dried and stored in petri dishes until the gravimetric analysis.

\section{Quantification of microplastics}

In the sequential washing experiments, the shed fibres were counted under an optical stereomicroscope (Nikon SMZ-1B, magnification $\times 35$ ) from $10 \%$ of the total effective area of the filter. The resulting fibre numbers were converted to the fibre number in the whole effluent water. The determination of fibre number has been detailed in Sillanpää and Sainio (2017).

Gravimetric analysis with a microbalance (Mettler Toledo XP56) was performed for the fibres released in the tumbledrying experiments. The measurement of sample mass was done as a duplicate, and the resulting mean value was normalised in relation to the mass of the textile.

Fibre lengths in sequential washing were studied by measuring 50 fibres per textile in a fifth wash under a stereomicroscope (Olympus SZ61) equipped with a digital camera (Olympus SC50). Olympus cellSens Entry-imaging software (version 2.3) was used to manually measure fibre lengths. Magnification ranged from $\times 0.67$ to $\times 4.5$, depending on the fibre length.

\section{Fibre traps}

Two commercial fibre traps were tested with three replicates of $100 \%$ polyester technical sports t-shirts. Guppyfriend washing bag (STOP! Micro Waste non-profit initiative) is a polyamide washing bag of size $45 \times 68 \mathrm{~cm}$, with a mesh size $30 \mu \mathrm{m}$ (measured by the authors under an optical microscope). The bag is used by washing the laundry inside the bag and removing the trapped fibres by hand after washing. In addition to the efficiency, the Guppyfriend was also tested for how clean the textiles stained with blackcurrant juice and cream cheese got after washing inside the bag. Cora Ball (Rozalia Project) is a laundry ball made of soft, recycled plastic material. It is $13 \mathrm{~cm}$ in diameter (Fig. 2). The ball is placed inside the washing drum, where the Cora Ball's narrow appendices trap fibres and piles. After washing, the stuck fibres are removed by hand. Both fibre traps have been designed to be easy-to-use and free of installation.

\section{Quality control}

Sample contamination was minimised in all stages of experiments and analysis. The surfaces in contact with the samples were thoroughly cleaned with Milli-Q water prior to use. The white lab coat was worn while treating the samples. To prevent contamination from the fibres in the laboratory air, the filters were kept in closed petri dishes whenever possible. The only time when the filters were uncovered was during drying which took place in a laminar flow hood. As mentioned in the "Machine washes and tumble drying" section, the empty washing machine was washed with detergent after each wash. Possible fibre contamination originating from a previous wash was detected by alternating textiles of different colour. Three blank samples were taken from these intermediate washes to assess the level of contamination from stray fibres of the previous washes.

The uncertainties were estimated for three measurements described above. The measurement uncertainty based on the maximum relative standard deviation of the series of three replicate subsamples was $20 \%$ for fibre number. For the mass measurement of fibre release in tumble dryings, the total uncertainty was assessed to be $25 \%$ due to the sampling uncertainty. The expanded measurement uncertainty (U) for fibre length was estimated to be $6 \mu \mathrm{m}$, i.e. $\leq 10 \%$ for the length range $55-565 \mu \mathrm{m}$, by using a Measurement Uncertainty kit (MUKit) software (Näykki et al. 2012).

\section{Results and discussion}

\section{Fibre release in sequential machine washes}

PES-ss shed the most fibres in the first wash $\left(6.3 \times 10^{6} \mathrm{~kg}^{-1}\right)$, followed by the technical t-shirts PES-ts1 $\left(3.1 \times 10^{6} \mathrm{~kg}^{-1}\right)$, 

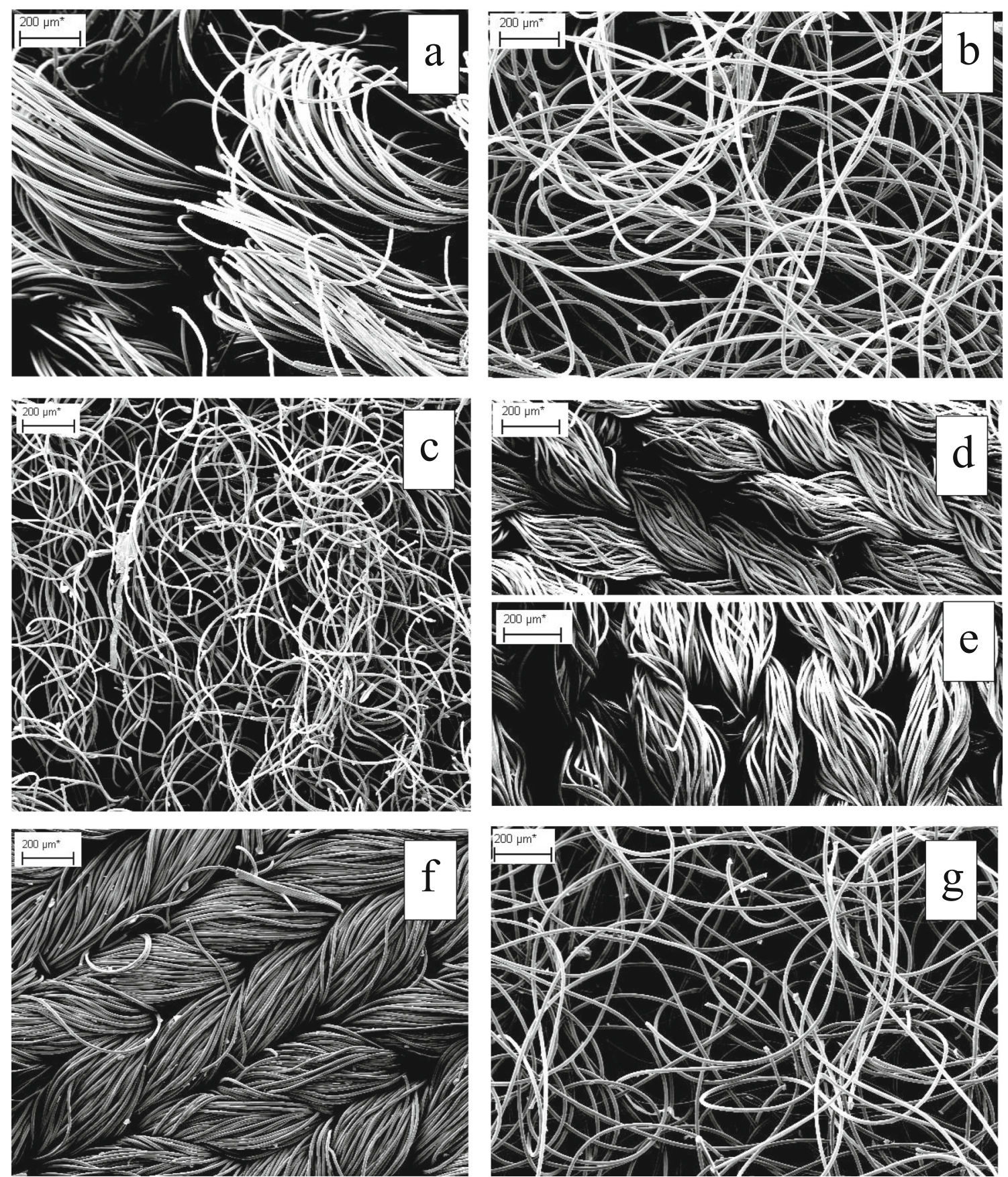

Fig. 1 Scanning electron microscopy (SEM) images of the sample textiles, with $\times 50$ magnification: a PES-fap; b PES-fnap; c PES-ss (the fleece layer); d PES-ts1; e PES-ts2; f PA-ts; $\mathbf{g}$ PAN-je

PES-ts2 $\left(1.4 \times 10^{6} \mathrm{~kg}^{-1}\right)$ and PA-ts $\left(5.2 \times 10^{5} \mathrm{~kg}^{-1}\right)$. The fleece textiles shed $1.9 \times 10^{5} \mathrm{~kg}^{-1}$ (PES-fnap) and $1.8 \times 10^{5}$ $\mathrm{kg}^{-1}$ (PES-fap). The lowest emissions in the first wash were from PAN-je $\left(1.0 \times 10^{5} \mathrm{~kg}^{-1}\right)$. As described in Table 2, the PES-ss fabric consists of two surface layers which are (1) woven fabric from 1.1dtex continuous filaments yarns (with elastane) and (2) a "fleece"-type fabric with piles generated by ripping of textured 0.8dtex filaments. Fibre release from the woven fabric is expected only from the seam and cut edges, whereas the breaking of individual piles from the fleece surface (or remains from the manufacturing) is an additional source of released fibres.

The emissions of all textiles decreased in the sequential washes, with emission values in the fifth wash falling between $1.9 \times 10^{4}$ and $1.9 \times 10^{5} \mathrm{~kg}^{-1}$. Figure 3 shows the normalised emission values for the synthetic textiles tested. The initial emission values decreased in the following washes and the value was less than $20 \%$ in the third wash except for PANje that had the normalised emission value between 0.22 and 0.47 in the second to fifth washes. The decreasing trends in the 
Fig. 2 The photo of a) the Cora Ball and b) the Guppyfriend washing bag inside the washing machine

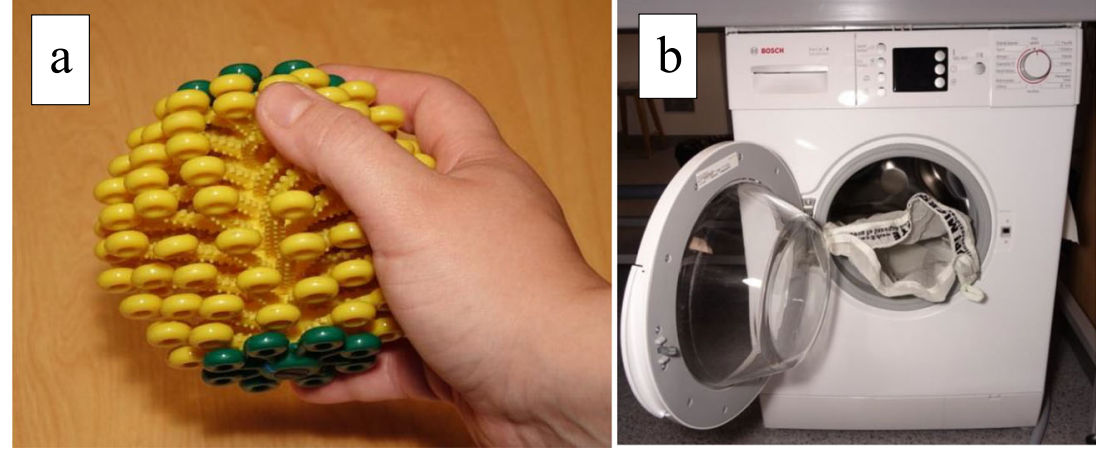

sequential washings have been earlier reported by Cesa et al. (2020), Belzagui et al. (2019), De Falco et al. (2019), Zambrano et al. (2019), Carney Almroth et al. (2018), Pirc et al. (2016) and Napper and Thompson (2016).

The length distributions of fibres released in the 5 th washes are shown in Fig. 4. The lengths varied greatly, from the shortest fibre length of $30 \mu \mathrm{m}$ to the longest one of 14,000 $\mu \mathrm{m}$. PES-fnap had the highest mean fibre length $(3500 \mu \mathrm{m})$, followed by PES-fap $(1400 \mu \mathrm{m})$. The mean fibre lengths of PES-ss and the technical t-shirts varied between 360 and 550 $\mu \mathrm{m}$. The means were somewhat higher than the corresponding medians, with the exception of PAN-je which had the mean fibre length of $1000 \mu \mathrm{m}$ but a clearly smaller median (360 $\mu \mathrm{m})$. The high mean of PAN-je is accounted for a few exceptionally long acryl fibres (the longest $14,000 \mu \mathrm{m}$ ). In terms of length distribution range, technical sports t-shirts and PES-ss had a narrower range than the other textiles tested. It was noted that PAN-je had the most variation not only in length, but also in width. These variations in fibre lengths between the textiles can most likely be explained by their textile and yarn characteristics.

The fibre length from PAN-je ranged between 60 and $14,000 \mu \mathrm{m}$, and it had a mean length of $1000 \mu \mathrm{m}$. PAN-je is a knitted product, manufactured from bean-shaped staple fibres that typically have a length between 60 and $100 \mathrm{~mm}$ and a diameter of $18-28 \mu \mathrm{m}$. The fibres are pulled out of the fabric construction and broken during washing due to the mechanical stress.

The fibres that were released from the technical t-shirts PES-ts and PA-ts manufactured from continuous filaments were mostly short, with a mean length of $480 \mu \mathrm{m}$ for PESts $1,550 \mu \mathrm{m}$ for PES-ts2 and $500 \mu \mathrm{m}$ for PA-ts. The fibre lengths for the t-shirts ranged between 30 and $1500 \mu \mathrm{m}$. The origin of these fibres was most likely both the cut edges of the fabric and the seams that contained damaged fibres produced during manufacturing when a needle pierced the fabric.

The fibre lengths from the polar fleece textiles might be explained by the looped pile heights of the fabric which is

Table 2 Descriptions of the fabric and yarn characteristics of the textile samples

\begin{tabular}{|c|c|c|c|}
\hline Sample & Description & Fabric & Yarn \\
\hline PES-fap & $\begin{array}{l}\text { Polar fleece fabric }(100 \% \\
\text { polyester })\end{array}$ & $\begin{array}{l}\text { Single jersey knitted fabric with raised, } \\
\text { looped piles on both sides, }\end{array}$ & $\begin{array}{l}\text { Jersey: false-twist textured 3dtex multifilament yarn } \\
\text { Piles: from flat (not-textured) 2dtex filaments }\end{array}$ \\
\hline PES-fnap & $\begin{array}{l}\text { Polar fleece blanket }(100 \% \\
\text { polyester) }\end{array}$ & $\begin{array}{l}\text { Single jersey knitted fabric with raised, } \\
\text { looped piles on both sides }\end{array}$ & $\begin{array}{l}\text { Jersey: false-twist textured 4dtex multifilament yarn } \\
\text { Piles: from flat (not-textured) 2dtex filaments }\end{array}$ \\
\hline PES-SS & $\begin{array}{l}\text { Composite fabric: two layers } \\
\text { laminated on a membrane } \\
\text { film } \\
\text { (1) Orange shell layer } \\
\text { (2) Purple fleece layer }(96 \% \\
\text { polyester, } 4 \% \text { elastane) }\end{array}$ & $\begin{array}{l}\text { Shell: Plain weave fabric } \\
\text { Fleece: Jersey knitted base fabric with } \\
\text { raised, looped piles on one side }\end{array}$ & $\begin{array}{l}\text { Plain weave: false-twist textured } 1.1 \mathrm{dtex} \text { PES multifilament } \\
\text { yarn with embedded } 15 \mathrm{dtex} \text { elastane fibres in the chain and } \\
\text { weft } \\
\text { Jersey: false-twist textured } 2.6 \mathrm{dtex} \text { multifilament yarn } \\
\text { Piles: from false-twist textured 0.8dtex filaments }\end{array}$ \\
\hline PES-ts & \multicolumn{3}{|c|}{ Four technical sport t-shirts ( $100 \%$ polyester) } \\
\hline PES-ts $1^{\text {a }}$ & Pink t-shirt & Single jersey knitted fabric & Stretch false-twist textured 0.9dtex multifilament yarn \\
\hline PES-ts $2^{b}$ & Green t-shirt & Pique knitted fabric & Stretch false-twist textured 2 dtex multifilament yarn \\
\hline PA-ts ${ }^{b}$ & $\begin{array}{l}\text { Technical sport t-shirt ( } 92 \% \\
\text { polyamide, } 8 \% \text { elastane })\end{array}$ & Single jersey knitted fabric & $\begin{array}{l}\text { Stretch false-twist textured } 1.5 \mathrm{dtex} \text { multifilament PA yarn with } \\
\text { elastane as rubber bands in the hip and shoulder }\end{array}$ \\
\hline PAN-je & Knitted jumper (100\% acryl) & Fluffy knitted (different knitting patterns) & 3 brown and one black oval $\sim 4.5$ dtex staple fibre yarn \\
\hline
\end{tabular}

${ }^{a}$ Seams were with cut edges but only partly covered with thread

${ }^{\mathrm{b}}$ Seams were with cut edges and covered with thread 
Fig. 3 The normalised emission values of released synthetic fibres in five sequential washes. The normalisation was done by dividing the released fibre number of each wash by that of the first wash

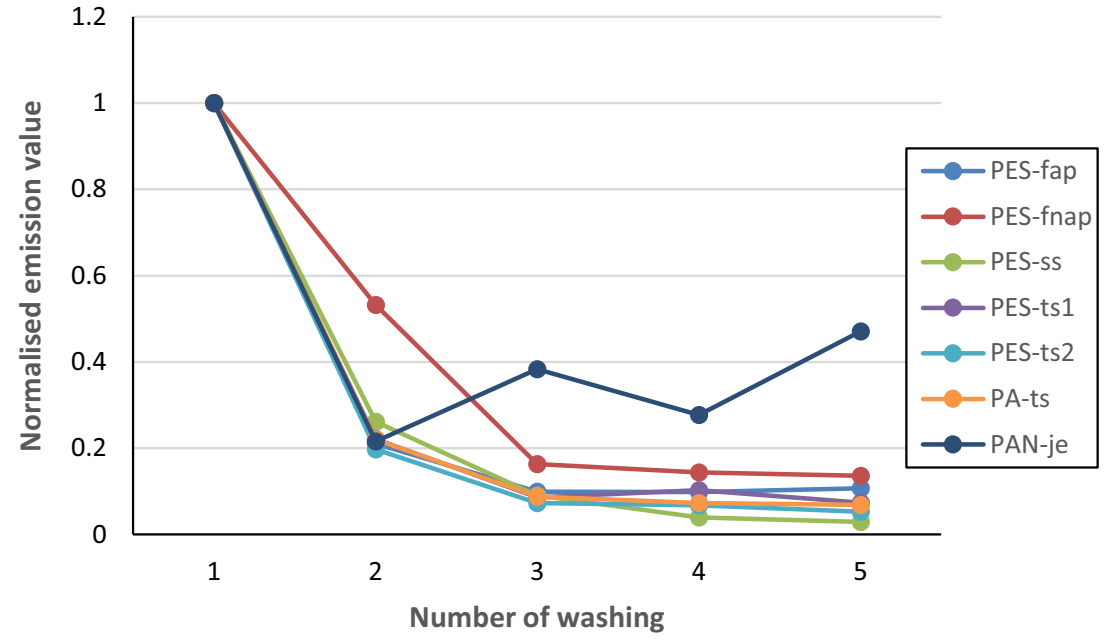

about half the length of the fibres forming the looped piles. The height of the piles on the one-sided fleece of the PES-ss fabric was about $1000 \mu \mathrm{m}$, and the released fibres had a mean length of $360 \mu \mathrm{m}$. The double-sided fleece PES-fap had piles with heights of $1000 \mu \mathrm{m}$ and $2000 \mu \mathrm{m}$, with the released fibres having a mean length of $1400 \mu \mathrm{m}$. The pile heights of the double-sided fleece PES-fnap were $900 \mu \mathrm{m}$ and $800 \mu \mathrm{m}$, but the measured mean fibre length was unexpectedly high $(3500 \mu \mathrm{m})$. These long fibres could be explained by a poor embedment of the piles in the fabric which enables longer fibres to be pulled out.

Previous studies have focused either the complete textile products or textile samples cut from synthetic fabrics. Pirc et al. (2016) studied the washing of a double-sided fleece blanket with a pile height of $1000 \mu \mathrm{m}$. They reported higher fibre lengths for the released fibres when compared with the present study: a mean fibre length of $5300 \mu \mathrm{m}$ and a wide fibre length distribution with lengths ranging from 300 to $25,000 \mu \mathrm{m}$ which refers to slightly longer fibres than in the present study. Hernandez et al. (2017) studied the fibre length distributions of two textiles samples cut from knitted (single jersey and interlock) polyester fabrics during five simulated home sequential washings. In comparison with the present study, they used two different polyester fabrics knitted from yarns made from staple fibres. The cut edges were folded and sealed with a thread. Their fibre size distributions in fifth washing were similar to those of technical t-shirts in the present study.

The pore size of the filter used for the filtration of the washing effluent in the present study $(0.7 \mu \mathrm{m})$ was close to
Fig. 4 The length distribution of fibres released in the 5 th washes $(n=50)$. The boundaries of the box indicate the 25 th and 75 th percentiles, the black line within the box signifies the median, the red line the mean, the whiskers the 10th and 90th percentiles, and the blue dots outlying points

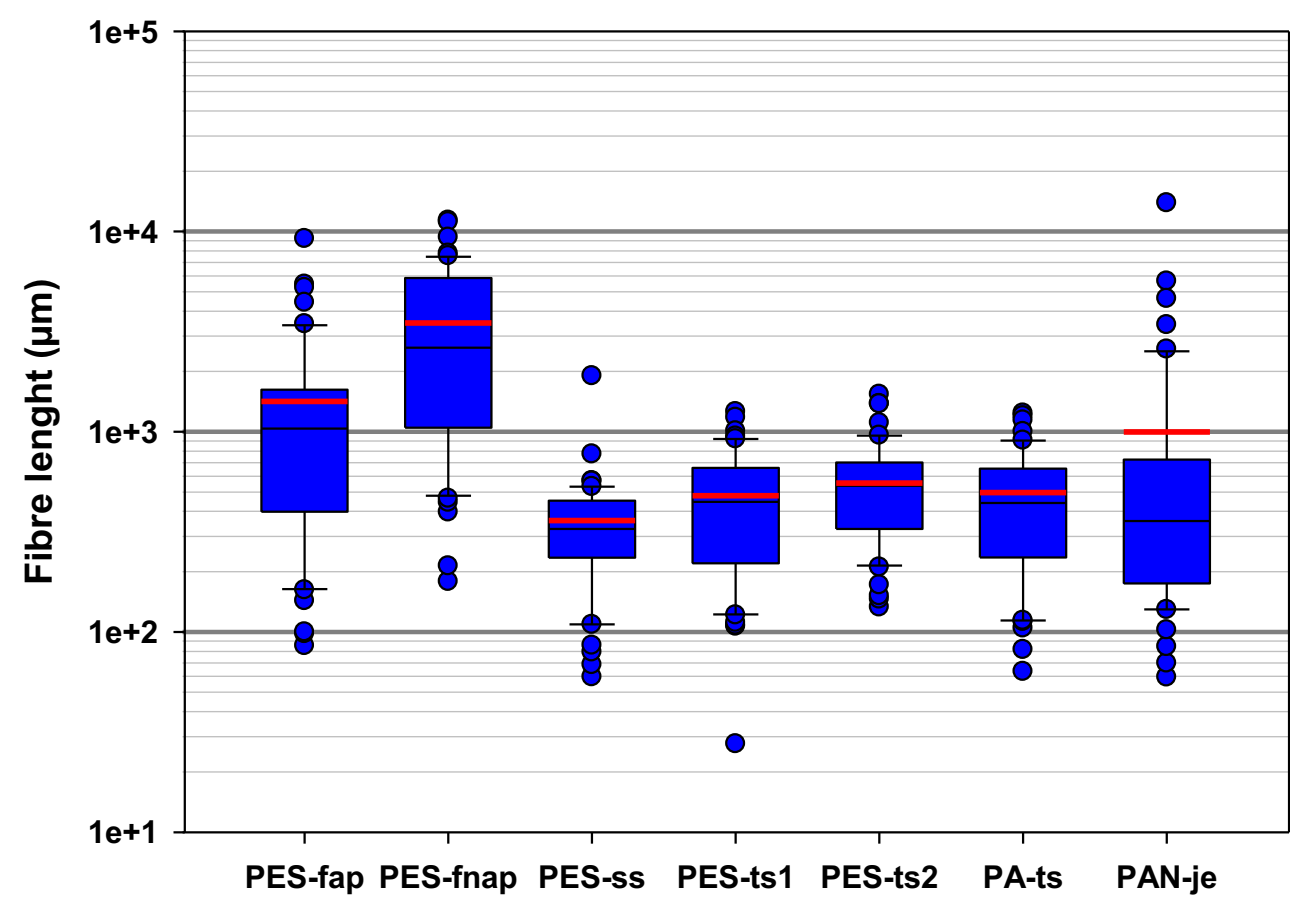


those $(0.2$ to $0.7 \mu \mathrm{m})$ used by Corami et al. (2020) and Hernandez et al. (2017) but smaller than those (20 to 200 $\mu \mathrm{m})$ used by Cesa et al. (2020), Belzagui et al. (2019), Kelly et al. (2019), De Falco et al. (2018), Hartline et al. (2016), Napper and Thompson (2016) and Pirc et al. (2016). In terms of fibre number per fabric mass, the smaller the filter pore size was, the higher the fibre emission values were reported. The highest fibre emissions were from the present study, Corami et al. (2020) and De Falco et al. (2018). All the mentioned studies had emission values reaching millions of fibres per textile mass $(\mathrm{kg})$.

\section{Fibre release in sequential tumble dryings}

As with the sequential washing, fibre emissions showed a decreasing trend also in sequential drying (Fig. 5), with some of the fibre emissions reaching a plateau within the five sequential dryings. The first tumble-drying released the most fibres in all the textiles: the highest emissions were from PES-fnap $(1700 \mathrm{mg} / \mathrm{kg})$, PES-fap $(690 \mathrm{mg} / \mathrm{kg})$ and PES-ss $(340 \mathrm{mg} / \mathrm{kg})$. All these three textiles were fleece or contained fleece that is the fabric with raised, looped piles. They were followed by the fluffy knitted PAN-je $(140 \mathrm{mg} / \mathrm{kg})$. The fabrics releasing the least fibres in the first drying were the PA-ts $(10 \mathrm{mg} / \mathrm{kg})$ and PES-ts $(22 \mathrm{mg} / \mathrm{kg}$, with PES-ts 1 and PES-ts2 textiles tumble dried together). The double-sided fleece textiles PES-fnap and PES-fap continued to release considerably more fibres than other textiles, and without stabilizing their emissions, throughout the sequential dryings. The technical tshirts PA-ts and PES-ts continued to release the least amount of fibres throughout the sequential dryings.

The high fibre emission values of PES-nfap, PES-fap and PES-ss during tumble drying (Fig. 5) result likely from the loosely knitted structure of the fabrics, i.e. that the fabrics have on their surface both raised fibre-ends and raised, looped piles. These kinds of loose fibres are susceptible to being broken off from the textile surface, for example due to mechanical stress from washing (Zambrano et al. 2019). In general, loosely knitted fibres are also easily entangled together to form pills on the textile surface (Hussain et al. 2008), for example during washing-drying cycles (Okubayashi and Bechtold 2005; Okubayashi et al. 2005). The formed pills can then be worn away from the textile surface due to mechanical stress. While fibre loss from pilling has been discussed in relation to machine wash (Napper and Thompson 2016), it should be also considered in relation to tumble drying.

PAN-je, manufactured from staple fibres, also has many raised fibre-ends (no piles) that should be susceptible to fibre loss during drying. This shows in the emission values of PANje in that they are placed between the other textiles. Finally, the technical t-shirts PA-ts and PES-ts, manufactured from continuous filaments, have "less hairy" and more firmly knitted textile surface without piles or multiple fibre-ends sticking out of the surface. This likely results in less fibre release than the other textile samples during tumble drying. The t-shirts only have fibre-ends sticking-out from their seams and from the cut edge of the fabric from which fibres might have been released during drying, as well as during washing.

For comparison of fibre emissions from washings and dryings, the fibre numbers from machine washes were converted to the fibre mass by multiplying the emission numbers by the fibre linear density (dtex values in Table 2) and the mean length of released fibres. The machine wash-to-tumble drying ratio of the fibres released from the fifth treatment is presented in Fig. 6. The ratios of polyester and polyamide technical tshirts are higher than 1 , which indicates the fibre release being larger in machine wash than in tumble drying. The other tested textiles had the ratio lower than 1 , which refers the tumble drying to be the dominating treatment in fibre release.

Fibre release can be accounted for two different mechanisms: (1) the detachment of already loose fibres from the fabric surface, produced for example from the manufacturing process of the fabric, and (2) the breaking-off of fibres from the fabric itself. Tumble drying the textiles was accompanied
Fig. 5 Fibre masses released from six different textiles in five sequential tumble dryings

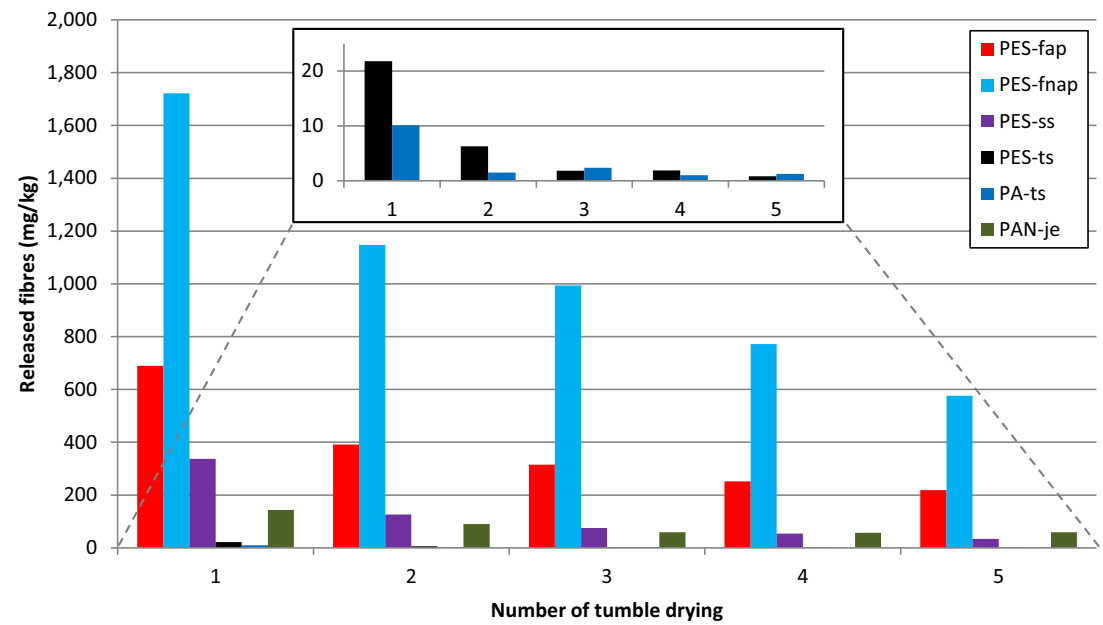


Fig. 6 The machine wash-totumble drying ratio of the fibres released from the fifth treatment of the six textiles

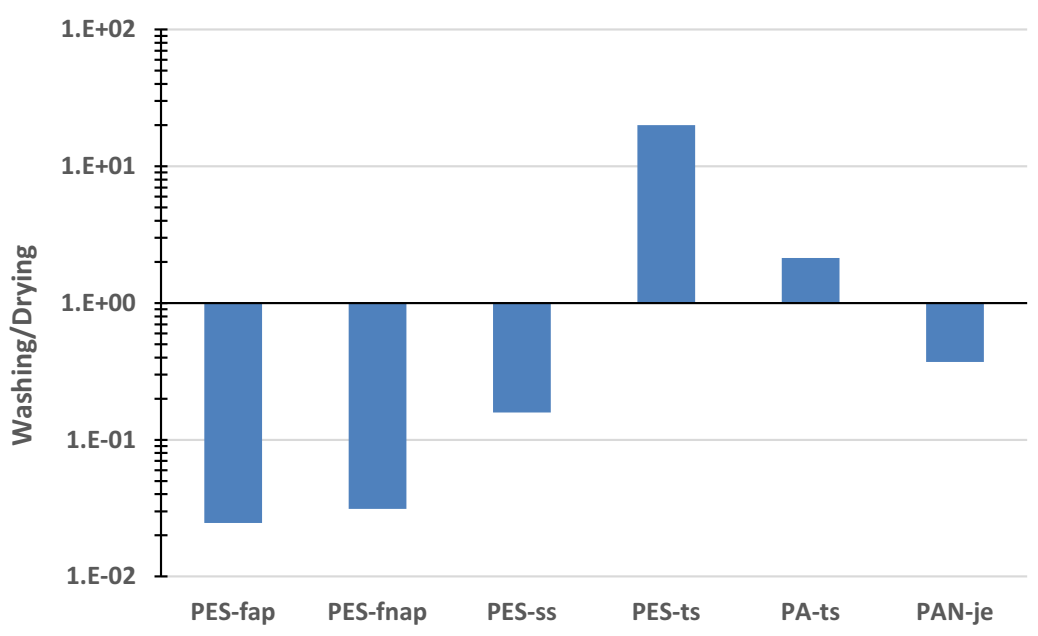

by more mechanical stress than when washing the textiles in water. Therefore, the breaking-off of fibres from the fabric itself during tumble drying is expected to be higher than during washing. Some fibres released during washing were already loose on the fabric surface or weakened from previous treatments to break off. The t-shirts were more firmly knitted fabrics with fibre-ends sticking-out only in the seam and the cut edges of the fabric. Also, loose fibres might have been generated during the stitching of the seam. The loose fibres, broken off from continuous filaments by a needle, may have been released during washing with declining fibre numbers during the sequential wash-and-drying cycles.

Pirc et al. (2016) is the only study where fibre release during tumble drying has been investigated. They treated six $100 \%$ polyester fleece blankets in ten sequential washand-drying cycles. Like in the present study, they observed a decreasing trend in the fibre emissions. The fibre emissions in the first drying (washing done with liquid detergent) was $200 \mathrm{mg} / \mathrm{kg}$ which then decreased to 61 $\mathrm{mg} / \mathrm{kg}$ in the fifth drying, and finally reaching $34 \mathrm{mg} / \mathrm{kg}$ in the tenth drying. For the first five dryings, they reported lower fibre emission values for fleece fabrics than the present study. The differences between these two studies are likely due to differences in fabric characteristics and drying conditions. The mesh size of the lint filter was larger $(180 \mu \mathrm{m})$ in Pirc et al. (2016) than in the present study $(60 \mu \mathrm{m})$ but also the drying program and the shape of the drying drum may have affected the fibre release. More research should be done on tumble drying to better understand the effects of different fabric characteristics and drying conditions on the fibre emissions during tumble drying.

It must be noted that the fibres released in the tumble drying will not be led straight into a wastewater treatment plant, unlike the fibres released in machine wash or washer dryers. Instead, the fibres are trapped in the tumble dryer's lint filter that is cleaned by hand, with a vacuum cleaner or washing with water. Thus, it is up to the consumer whether the trapped fibres end up into the trash or sewage water. O'Brien et al. (2020) have shown that tumble drying releases microplastic fibres into indoor air, though the concentrations were low (1.6 \pm 1.8 fibres $/ \mathrm{m}^{3}$ ) in their study. It is worth mentioning that the residence time of large particles/fibres (much larger than 10 $\mu \mathrm{m})$ is typically short in the air and therefore they deposit in the vicinity of their emission source.

\section{Efficiency of fibre traps}

The collection efficiencies of two commercial fibre traps are presented in Fig. 7. The Guppyfriend clearly reduces fibre emissions during washing, with $39 \%$ reductions observed with fibre numbers. It should be noted that the collection efficiency is likely higher for the loosely knitted textiles that release longer fibres than the firmly knitted textiles studied here. The Guppyfriend did not prevent the stains of blackcurrant juice and cream cheese from being removed from the textile. Thus, the Guppyfriend can be used to reduce fibre emissions without compromising cleaning efficiency.

The Cora Ball trapped $10 \%$ of the short polyester fibres studied here (Fig. 7). Mcllwraith et al. (2019) has also investigated the collection efficiency of Cora Ball. They found that Cora Ball mitigated fibre emissions by $26 \%$ on a basis of fibre number. The difference between the two studies can be explained by the different length of studied fibre (longer than $100 \mu \mathrm{m}$ in Mcllwraith et al. 2019), since the trapping efficiency of Cora Ball increases with the size (length and lint) of fibres.

The overall effectiveness of a fibre trap to mitigate microplastic pollution is greatly impacted by their user-friendliness. Herweyers et al. (2020) examined the perceptions and attitudes of customers toward products that mitigate fibre emissions from domestic washings. Based on questionnaires 
Fig. 7 The number of the released polyester fibres with and without a the Guppyfriend washing bag and $\mathbf{b}$ the Cora Ball. Mean \pm SD of three replicate samples a

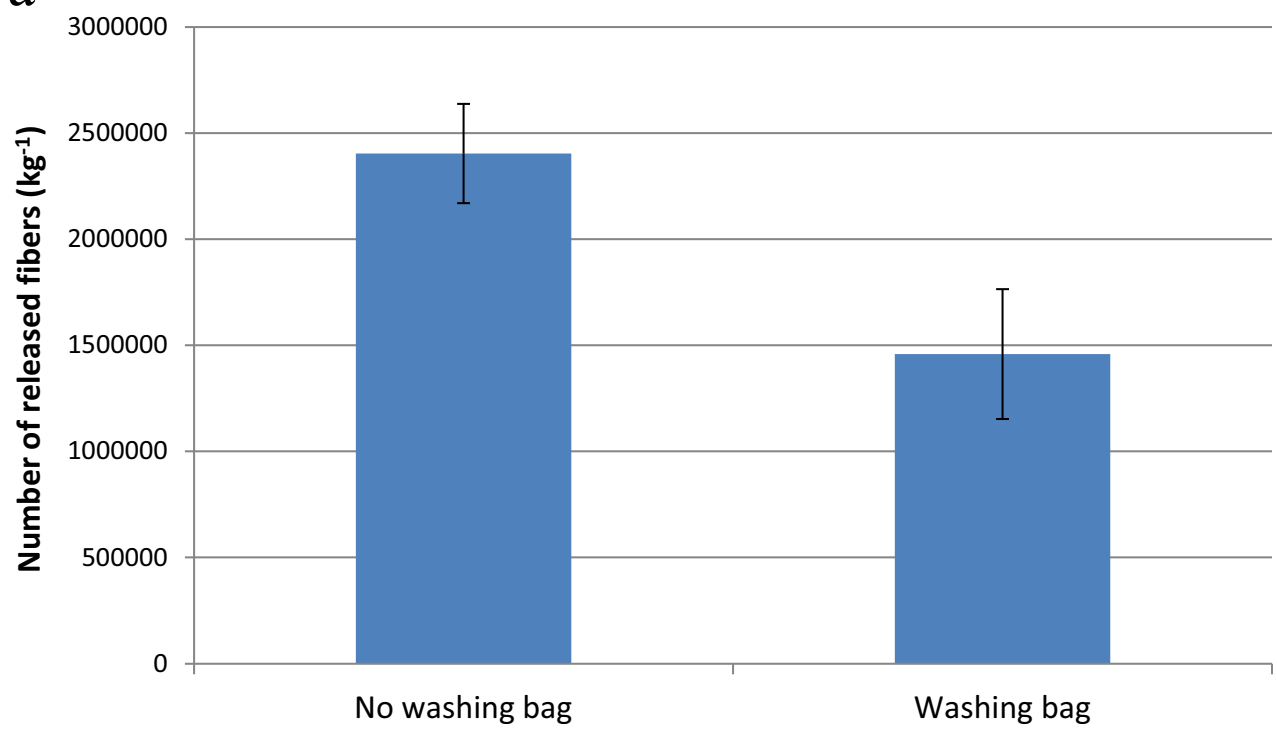

b

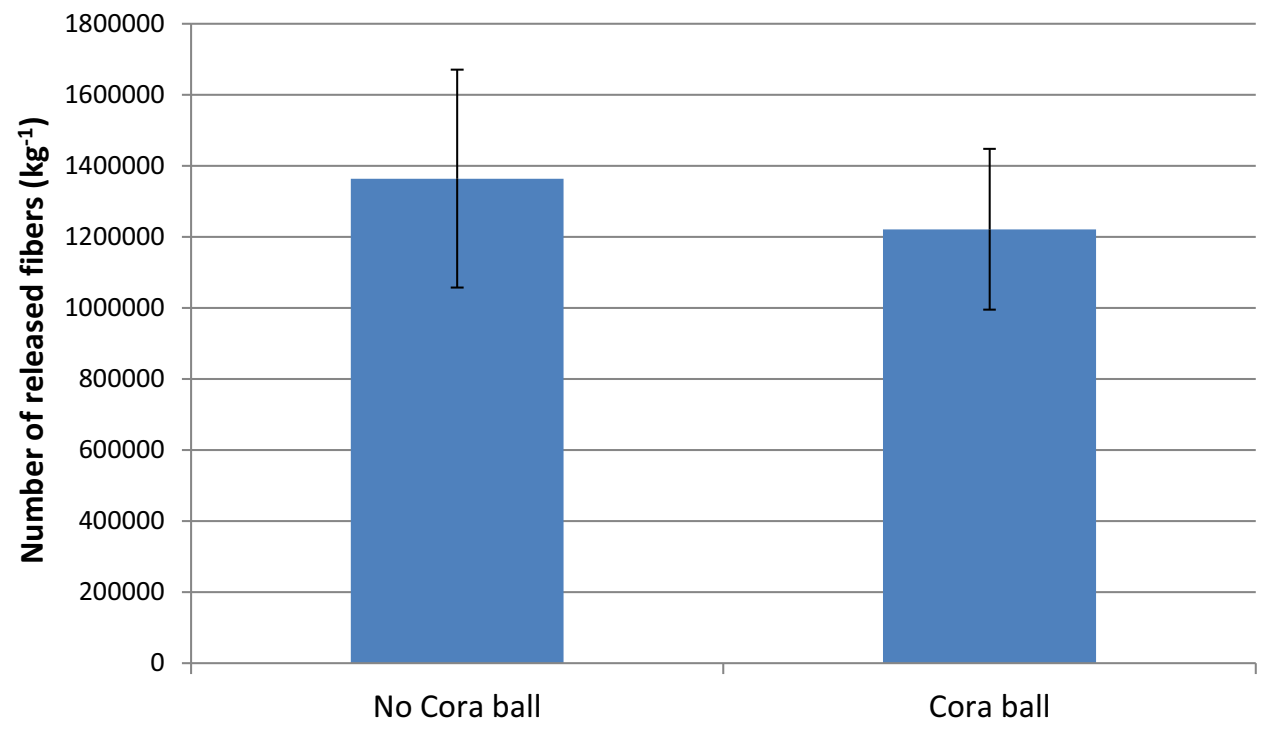

$(n=411)$ and user observations with interviews $(n=8)$, they found that the effectiveness and durability of a product followed by its usability, with special focus on convenience, were the most important factors in convincing people to use the product. They concluded that to keep people using the product for a long time, the product should be simple-to-use and user friendly. With both Cora Ball and Guppyfriend, the consumer needs to both clean the traps and dispose the collected fibres by hand. However, compared with other commercial fibre traps like the external Lint LUV-R filter, Cora Ball and Guppyfriend do not need to be installed or similarly maintained. There is also no danger of blockage when a filter is not changed often enough. Overall, there is a lower threshold for a consumer to purchase a Cora Ball or a Guppyfriend than an external filter to combat fibre emissions during washing.

\section{Summary and conclusions}

This study presented the emissions of seven synthetic textile fibres discharged from five sequential machine washes and tumble dryings. In addition, two commercial fibre traps were tested for how effectively they can catch the fibres released during the machine wash. In the first wash, the number of released fibres ranged from $1.0 \times 10^{5}$ to 6.3 $\times 10^{6} \mathrm{~kg}^{-1}$. The mass range in the first tumble drying 
was from 10 to $1700 \mathrm{mg} / \mathrm{kg}$. Overall, the fibre emissions exhibited a decreasing trend in both sequential washes and dryings. The fibre lengths from sequential washing showed that the fleece fabrics released, on average, longer fibres than the technical sports t-shirts.

The GuppyFriend washing bag and the Cora Ball trapped $39 \%$ and $10 \%$ of the polyester fibres discharged in washings, respectively. Thus, both traps mitigate the emissions, they are easy-to-use and free of installation, but they are not as effective as consumers may assume. As in the case of fibres caught in tumble drying, it is up to the consumer whether the trapped fibres end up into the trash or sewage water. This shows that new technical solutions can decrease the fibre emissions, but the consumer choice, habits and education play also important roles.

Acknowledgements We thank especially Michael Stark (a man-made fibre expert in retirement, Freiburg, Germany) and Ruth Hörmann (Trevira GmbH, Bobingen, Germany) for the generous support and expert help with the analyses of the textile samples. Ms. Minna Sepponen (Finnish Environment Institute) is acknowledged for her technical help during the experiments, Mr. Timo Vänni for the photographs (Fig. 2) and Dr. Teemu Näykki for the uncertainty estimation of fibre length measurement. We also thank the STOP! Micro Waste for donating us the Guppyfriend washing bag used in the present study. This work was supported by Maa- ja Vesitekniikan Tuki ry and the Emil Aaltonen Foundation.

Authors' contributions Niina Kärkkäinen: methodology, formal analysis and investigation, writing - original draft preparation, and funding acquisition.

Markus Sillanpää: conceptualisation, formal analysis and investigation, writing — original draft preparation, writing — review and editing, funding acquisition, resources, and supervision.

Funding Open Access funding provided by Finnish Environment Institute (SYKE). This work was supported by Maa- ja Vesitekniikan Tuki ry, the Emil Aaltonen Foundation and Finnish Environment Institute.

Data availability Not applicable.

\section{Compliance with ethical standards}

Competing interests The authors declare that they have no conflict interest.

Research involving human participants and/or animals Not applicable.

Consent to participate All authors have given consent to their contribution.

Consent to publish All authors have agreed with the content and all have given explicit consent to publish.

Open Access This article is licensed under a Creative Commons Attribution 4.0 International License, which permits use, sharing, adaptation, distribution and reproduction in any medium or format, as long as you give appropriate credit to the original author(s) and the source, provide a link to the Creative Commons licence, and indicate if changes were made. The images or other third party material in this article are included in the article's Creative Commons licence, unless indicated otherwise in a credit line to the material. If material is not included in the article's Creative Commons licence and your intended use is not permitted by statutory regulation or exceeds the permitted use, you will need to obtain permission directly from the copyright holder. To view a copy of this licence, visit http://creativecommons.org/licenses/by/4.0/.

\section{References}

Alomar C, Deudero S (2017) Evidence of microplastic ingestion in the shark Galeus melastomus Rafinesque, 1810 in the continental shelf off the western Mediterranean Sea. Environ Pollut 223:223-229

Belzagui F, Crespi M, Álvarez A, Gutiérrez-Bouzán C, Vilaseca M (2019) Microplastics' emissions: microfibers' detachment from textile garments. Environ Pollut 248:1028-1035

Carmichael A (2015) Man-made fibers continue to grow. Text World 165(1):20-22

Carney Almroth B, Åström L, Roslund S, Petersson H, Johansson M, Persson N (2018) Quantifying shedding of synthetic fibers from textiles; a source of microplastics released into the environment. Environ Sci Pollut Res 25(2):1191-1199

Carr SA, Liu J, Tesoro AG (2016) Transport and fate of microplastic particles in wastewater treatment plants. Water Res 91:174-182

Cesa FS, Turra A, Checon HH, Leonardi B, Baruque-Ramos J (2020) Laundering and textile parameters influence fibers release in household washings. Environ Pollut 257:113553

Cincinelli A, Scopetani C, Chelazzi D, Lombardini E, Martellini T, Katsoyiannis A, Fossi MC, Corsolini S (2017) Microplastic in the surface waters of the Ross Sea (Antarctica): occurrence, distribution and characterization by FTIR. Chemosphere 175:391-400

Corami F, Rosso B, Bravo B, Gambaro A, Barbante C (2020) A novel method for purification, quantitative analysis and characterization of microplastic fibers using Micro-FTIR. Chemosphere 238:124564

De Falco F, Gullo MP, Gentile G, Di Pace E, Cocca M, Gelabert L, Brouta-Agnésa M, Rovira A, Escudero R, Villalba R, Mossotti R, Montarsolo A, Gavignano S, Tonin C, Avella M (2018) Evaluation of microplastic release caused by textile washing processes of synthetic fabrics. Environ Pollut 236:916-925

De Falco F, Di Pace E, Cocca M, Avella M (2019) The contribution of washing processes of synthetic clothes to microplastic pollution. Sci Rep 9(1):6633

Fischer EK, Paglialonga L, Czech E, Tamminga M (2016) Microplastic pollution in lakes and lake shoreline sediments - a case study on Lake Bolsena and Lake Chiusi (central Italy). Environ Pollut 213(C):648-657

Galafassi S, Nizzetto L, Volta P (2019) Plastic sources: a survey across scientific and grey literature for their inventory and relative contribution to microplastics pollution in natural environments, with an emphasis on surface water. Sci Total Environ 693:133499

Hartline NL, Bruce NJ, Karba SN, Ruff EO, Sonar SU, Holden PA (2016) Microfiber masses recovered from conventional machine washing of new or aged garments. Environ Sci Technol 50(21): 11532-11538

Henry B, Laitala K, Klepp IG (2019) Microfibres from apparel and home textiles: prospects for including microplastics in environmental sustainability assessment. Sci Total Environ 652:483-494

Hernandez E, Nowack B, Mitrano DM (2017) Polyester textiles as a source of microplastics from households: a mechanistic study to understand microfiber release during washing. Environ Sci Technol 51(12):7036-7046

Herweyers L, Catarci Carteny C, Scheelen L, Watts R, Du Bois E (2020) Consumers' perceptions and attitudes toward products preventing 
microfiber pollution in aquatic environments as a result of the domestic washing of synthetic clothes. Sustainability 12(6):2244

Hurley RR, Woodward JC, Rothwell JJ (2017) Ingestion of microplastics by freshwater tubifex worms. Environ Sci Technol 51(21):12844 12851

Hussain T, Ahmed S, Qayum A (2008) Effect of different softeners and sanforising treatment on pilling performance of polyester/viscose blended fabrics. Color Technol 124(6):375-378

Kelly MR, Lant NJ, Kurr M, Burgess JG (2019) Importance of watervolume on the release of microplastic fibers from laundry. Environ Sci Technol 53(20):11735-11744

Lares M, Ncibi MC, Sillanpää M, Sillanpää M (2018) Occurrence, identification and removal of microplastic particles and fibers in conventional activated sludge process and advanced MBR technology. Water Res 133:236-246

Lee H, Shim WJ, Kwon J-H (2014) Sorption capacity of plastic debris for hydrophobic organic chemicals. Sci Total Environ 470-471:15451552

Lusher AL, Tirelli V, O'Connor I, Officer R (2015) Microplastics in Arctic polar waters: the first reported values of particles in surface and sub-surface samples. Sci Rep 5(1):14947-14947

Magnusson K, Norén F (2014) Screening of microplastic particles in and down-stream a wastewater treatment plant, Report C55. Swedish Environmental Research Institute, Sweden http://urn.kb.se/resolve? urn=urn:nbn:se:naturvardsverket:diva-2226. Accessed 8 Jan 2020

Mani T, Hauk A, Walter U, Burkhardt-Holm P (2015) Microplastics profile along the Rhine River. Sci Rep 5(1):17988-17988

McIlwraith HK, Lin J, Erdle LM, Mallos N, Diamond ML, Rochman CM (2019) Capturing microfibers-marketed technologies reduce microfiber emissions from washing machines. Mar Pollut Bull 139:40-45

Michielssen MR, Michielssen ER, Ni J, Duhaime MB (2016) Fate of microplastics and other small anthropogenic litter (SAL) in wastewater treatment plants depends on unit processes employed. Environ Sci Water Res Technol 2(6):1064-1073

Murphy F, Ewins C, Carbonnier F, Quinn B (2016) Wastewater treatment works (WwTW) as a source of microplastics in the aquatic environment. Environ Sci Technol 50(11):5800-5808

Napper IE, Thompson RC (2016) Release of synthetic microplastic plastic fibres from domestic washing machines: effects of fabric type and washing conditions. Mar Pollut Bull 112(1-2):39-45

Näykki T, Virtanen A, Leito I (2012) Software support for the Nordtest method of measurement uncertainty evaluation. Accred Qual Assur 17:603-612

O'Brien S, Okoffo ED, O'Brien JW, Ribeiro F, Wang X, Wright SL, Samanipour S, Rauert C, Toapanta TYA, Albarracin R, Thomas KV (2020) Airborne emissions of microplastics fibres from domestic laundry dryers. Sci Total Environ 747:141175

Okubayashi S, Bechtold T (2005) A pilling mechanism of man-made cellulosic fabrics - effects of fibrillation. Text Res J 75(4):288-292

Okubayashi S, Campos R, Rohrer C, Bechtold T (2005) A pilling mechanism for cellulosic knit fabrics - effects of wet processing. J Text Inst 96(1):37-41
Pirc U, Vidmar M, Mozer A, Kržan A (2016) Emissions of microplastic fibres from microfibre fleece during domestic washing. Environ Sci Pollut Res 23:22206-22211

Plastics - the Facts (2019) An analysis of European plastics production, demand and waste data, https://www.plasticseurope.org/download file/force/3183/181. Accessed 26 March 2020

Rodrigues M, Abrantes N, Gonçalves F, Nogueira H, Marques J, Gonçalves A (2018) Spatial and temporal distribution of microplastics in water and sediments of a freshwater system (Antuã River, Portugal). Sci Total Environ 633:1549-1559

Scheurer M, Bigalke M (2018) Microplastics in Swiss floodplain soils. Environ Sci Technol 52(6):3591-3598

Selonen S, Dolar A, Kokalj AJ, Skalar T, Dolcet LP, Hurley R, van Gestel CAM (2020) Exploring the impacts of plastics in soil - the effects of polyester textile fibers on soil invertebrates. Sci Total Environ 700: 134451

Setälä O, Fleming-Lehtinen V, Lehtiniemi M (2014) Ingestion and transfer of microplastics in the planktonic food web. Environ Pollut 185: $77-83$

Sillanpää M, Sainio P (2017) Release of polyester and cotton fibres from textiles in machine washing. Environ Sci Pollut Res 24:1931319321

Sruthy S, Ramasamy EV (2017) Microplastic pollution in Vembanad lake, Kerala, India: the first report of microplastics in lake and estuarine sediments in India. Environ Pollut 222:315-322

Su L, Cai H, Kolandhasamy P, Wu C, Rochman CM, Shi H (2018) Using the Asian clam as an indicator of microplastic pollution in freshwater ecosystems. Environ Pollut 234:347-355

Talvitie J, Mikola A, Koistinen A, Setälä O (2017) Solutions to microplastic pollution - removal of microplastics from wastewater effluent with advanced wastewater treatment technologies. Water Res 123:401-407

van der Hal N, Ariel A, Angel DL (2017) Exceptionally high abundances of microplastics in the oligotrophic Israeli Mediterranean coastal waters. Mar Pollut Bull 116:151-155

Wang C, Zhao J, Xing B (2020) Environmental source, fate and toxicity of microplastics. J Hazard Mater (in press):124357. https://doi.org/ 10.1016/j.jhazmat.2020.124357

Yang L, Qiao F, Lei K, Li H, Kang Y, Cui S, An L (2019) Microfiber release from different fabrics during washing. Environ Pollut 249: 136-143

Zambrano MC, Pawlak JJ, Daystar J, Ankeny M, Cheng JJ, Venditti RA (2019) Microfibers generated from the laundering of cotton, rayon and polyester based fabrics and their aquatic biodegradation. Mar Pollut Bull 142:394-407

Zhang S, Yang X, Gertsen H, Peters P, Salánki T, Geissen V (2018) A simple method for the extraction and identification of light density microplastics from soil. Sci Total Environ 616-617:1056-1065

Publisher's note Springer Nature remains neutral with regard to jurisdictional claims in published maps and institutional affiliations. 